Published in final edited form as:

Expert Rev Endocrinol Metab. 2018 March ; 13(2): 107-118. doi:10.1080/17446651.2018.1445524.

\title{
Recent advances in the diagnosis and management of Gaucher disease
}

\author{
Sam E. Gary\#, Emory Ryan\#, Alta M. Steward, and Ellen Sidransky \\ Medical Genetics Branch, NHGRI, NIH, Bethesda, MD, USA \\ \# These authors contributed equally to this work.
}

\begin{abstract}
Introduction: Gaucher disease, the autosomal recessive deficiency of the lysosomal enzyme glucocerebrosidase, is associated with wide phenotypic diversity including non-neuronopathic, acute neuronopathic, and chronic neuronopathic forms. Overlap between types can render definitive diagnoses difficult. However, differentiating between the different phenotypes is essential due to the vast differences in clinical outcomes and response to therapy. Genotypic information is helpful, but cannot always be used to make clinical predictions. Current treatments for Gaucher disease, including enzyme replacement therapy and substrate reduction therapy, can reverse many of the non-neurological manifestations, but these therapies must be administered continually and are extremely costly.
\end{abstract}

Areas covered: We reviewed the literature concerning the varied clinical presentations of Gaucher disease throughout the lifetime, along with treatment options, management goals, and current and future research challenges. A PubMed literature search was performed for relevant publications between 1991 to January 2018.

Expert commentary: Interest and research in the field of Gaucher disease is rapidly expanding. However, significant barriers remain in our ability to predict phenotype, assess disease progression using objective biomarkers, and determine optimal treatment strategy on an individual basis. As the field grows, we anticipate identification of genetic modifiers, new biomarkers, and smallmolecule chaperone therapies, which may improve patient quality of life.

\section{Keywords}

Gaucher disease; glucocerebrosidase; genotype/phenotype correlation; enzyme replacement therapy; substrate reduction therapy; newborn screening; parkinsonism; chaperones; biomarkers

CONTACT Ellen Sidransky sidranse@mail.nih.gov Medical Genetics Branch, National Human, Genome Research Institute, NIH, Building 35A, Room 1E623, Convent Drive, MSC 3708, Bethesda, MD, 20892-3708, USA,.

Declaration of interest

The authors have no relevant affiliations or financial involvement with any organization or entity with a financial interest in or financial conflict with the subject matter or materials discussed in the manuscript. This includes employment, consultancies, honoraria, stock ownership or options, expert testimony, grants or patents received or pending, or royalties. Peer reviewers on this manuscript have no relevant financial or other relationships to disclose. 


\section{Introduction}

Gaucher disease (GD) is an autosomal recessive lysosomal storage disorder (LSD) caused by mutations in $G B A 1$, resulting in a deficiency of the enzyme glucocerebrosidase (GCase; E. C3.2.1.45). GD is a rare pan-ethnic disease that affects approximately 1 in 50,000 to 1 in 100,000 people in the general population. Although it is a single-gene disorder, there is wide variation in the degree and severity of symptoms. The phenotypes encountered have historically been classified by type and severity of neurological involvement. Type $1 \mathrm{GD}$ (GD1) is defined as the non-neuronopathic subclass and can present at any age. GD1 is far more common in individuals of Eastern and Central European (Ashkenazi) Jewish heritage, where the carrier frequency is as high as 1 in 16 [1]. Acute neuronopathic GD (GD2) generally presents perinatally or within the first year of life and is characterized by rapid neurological decline. Chronic neuronopathic GD (GD3) often has an onset in early childhood, with a highly variable spectrum of associated neurological and non-neurological manifestations. The defining and most common feature of GD3 is slowing of the horizontal saccadic eye movements [2].

While GD was first described almost 140 years ago, the past two decades have produced great advances in our appreciation of the phenotypic spectrum associated with this disorder, as well as our ability to treat patients. These new insights affect the diagnosis and treatment of patients at both ends of the age spectrum. This review aims to convey the varied clinical presentations along with the evolving diagnostic and treatment options for pediatric and adult patients with GD.

\section{Pediatric diagnosis at different ages}

Establishing the initial diagnosis of GD can be challenging because of the highly variable phenotypic presentations and the overlap with other disorders. This is further complicated by an increasing number of asymptomatic children being diagnosed through genetic screenings. As treatment for GD can be costly, time consuming, and invasive, deciding when and how to begin treatment can be difficult. A clearer understanding of the nuances of different disease presentations at different ages (Box 1) can lead to better treatment and patient/parental counseling.

\subsection{Prenatal screening}

Although prenatal screening for lysosomal storage disorders (LSDs) is being performed more frequently in specific populations, there is no standard list of LSDs that are screened for across centers. While enzymatic assays can identify patients with different LSDs, typically these assays demonstrate limited reliability for identifying carriers. Population screening is now typically done by DNA analyses. Most often, GD is included in a panel of disorders that are targeted to the higher risk Ashkenazi Jewish population. In Israel, where such panels are frequently offered, more than half of the pediatric GD diagnoses since 2000 were a result of screening, rather than symptomatic presentation [3]. In this population, screening for 4-8 common $G B A 1$ mutations can identify up to $95 \%$ of mutant alleles, making such screens quite effective. In populations with different ethnic backgrounds, these panels identify a far lower percentage of disease-causing mutations. Therefore, sequencing 
of the entire $G B A 1$ gene is recommended. This is not trivial, as the presence of a nearby highly homologous pseudogene complicates genotypic analyses, limiting wide-scale genomic sequencing on a population level. In affected families, where the $G B A 1$ mutations are known, prenatal screening can easily be performed to detect specific mutations in carriers. Subsequent pregnancies can be screened via chorionic villi samples or amniotic fluid. If the mutations are not known, prenatal diagnosis can be performed by enzymatic assays in an experienced laboratory.

\subsection{Newborn screening}

In the United States, several states have begun pilot programs that screen for selected LSDs. Currently, Missouri, New York, and Illinois have introduced programs which include GD among other LSDs. Several other states have a more limited approach or are still considering implementation of testing [4,5]. Newborn screening for disorders like GD is a highly debated topic, as such screens will also identify infants who may be asymptomatic for years or even a lifetime. In a disorder like GD, where many affected individuals never reach medical attention, the negative impact of knowing about this chronic condition, including parental anxiety and financial implications, can be substantial. Others argue that this impact is greatly overshadowed by the benefits of early symptom recognition and treatment, which may prevent numerous long-term sequelae [6].

\subsection{Children identified at birth without symptoms}

Prenatal and newborn screenings, as well as early screening in families of children with GD, have led to the identification of a cohort of children with GD, who are asymptomatic. There have been three studies describing these children. The first, conducted in New York, followed 38 patients aged $1-18$ years (mean age at last visit $6.9 \pm 4.1$ years) who were diagnosed with GD1 either prenatally or postnatally by molecular genetic testing. Only a minority had hematological (5\%), bone (15\%), or linear growth (19\%) issues, and just $12 \%$ displayed splenomegaly. Disease severity, assessed by the pediatric Gaucher severity score, remained stable and within the mild disease range for most (95\%). During the 1-18 years of follow-up, treatment was recommended for four of the children [7]. A similar study, conducted in Israel, followed 40 children diagnosed through screening since 2000 [3]. Only 4 of the 40 required therapy. A third study, reporting the results of newborn screening for LSDs in Illinois, described five infants with GD. None required treatment in the 15-month follow-up period [4]. It is likely that asymptomatic children will be identified with greater frequency in the coming years. Longitudinal studies following these cohorts will be imperative. Currently, routine monitoring of asymptomatic individuals identified through screening is recommended, so treatment can be initiated quickly, should symptoms develop.

\subsection{Symptomatic presentations in the prenatal and neonatal period}

Symptoms appearing prenatally or in the neonatal period are usually associated with GD2, though presentations differ. Hydrops fetalis, the abnormal accumulation of fluid in at least two body areas, has been described in cases of GD2 and may present at birth or perinatally [8]. GD and other LSDs remain a small but significant cause of hydrops fetalis, with some variability in incidence based on population [9-12]. As such, GD is not usually considered until a couple experiences multiple spontaneous abortions or perinatal deaths. The etiology 
of approximately $20 \%$ of cases of hydrops fetalis remains unknown. Testing for GD and other LSDs may elucidate the underlying cause in some cases and inform prenatal counseling [9].

Congenital ichthyosis, the collodion baby phenotype, can also be associated with GD2. The collodion phenotype presents clinically at birth as a thick and shiny membrane, resembling cellophane wrap, covering the skin. This is also associated with other autosomal recessive conditions and, in GD, is a hallmark of severe neuronopathic disease [13,14]. While dysmorphic features are not generally associated with GD, when present, they are most often associated with the collodion baby phenotype [15].

Other infants with GD2 may present in the neonatal period with petechiae [13], blueberry muffin lesions, oozing, or retinal bleeding, secondary to thrombocytopenia. Many also have massive hepatosplenomegaly. In the newborn nursery, affected infants characteristically have stridor, poor suck, and difficulty handling secretions. GD2 is further characterized by rapid neurological decline, manifesting as brain stem dysfunction, which may include supranuclear gaze palsy, irritability, hypertonia, and hypokinesia. The progression of symptoms typically includes dysphagia, stridor, pyramidal signs, failure to thrive, cachexia, and convergent strabismus, with death occurring within the first months to years of life $[14,16]$.

\subsection{Symptomatic presentations in the first year of life}

Both acute and chronic neuronopathic, as well non-neuronopathic GD, may manifest in middle-to-late infancy. An accurate assessment of the phenotype is essential, as the difference in prognosis is striking (Figure 1).

In classic GD2, infants may appear normal during the immediate newborn period but begin to develop symptoms as described in the above section regarding neonatal onset, with death generally ensuing in the first 18 months. In recent years, more aggressive management including tracheostomy, gastrostomy, and enzyme replacement therapy (ERT) has increased the lifespan. However, arrest or regression of developmental milestones, seizures, and myoclonus usually follow $[14,16]$. While the visceral symptoms can be improved with ERT, there is little impact on neurodegeneration, as ERT does not cross the blood-brain barrier (BBB).

Patients with GD3 often present during the first year of life with massive organomegaly, anemia or thrombocytopenia, and a horizontal supranuclear gaze palsy. Most children meet developmental milestones, though their ability to crawl or walk can be impeded by their massive organomegaly. These children, in contrast to those with GD2, show remarkable improvement with early ERT initiation. Dramatic reversal of non-neurological manifestations, rapid catch-up of motor skills, and weight gain are frequently seen. In GD3 patients with neurodegeneration, progression, while not affected by any available treatment, is markedly slower than in GD2.

Patients with GD1 can also present in the first year of life. Usually, they are first noted to have organomegaly or cytopenia, often following an unrelated viral illness. 
In recent years, it has become possible to establish the diagnosis of GD using dried blood spot analyses [17]. This has enabled physicians to diagnose patients who do not have access to appropriate testing facilities in geographically remote regions. These dried blood spots can also be used to measure glucosylsphingosine levels, which show promise as a biomarker for disease severity and response to treatment.

\subsection{Symptomatic presentations in childhood and adolescence}

Both GD1 and GD3 can present in the pediatric years, though GD1 is more common. A recent survey of 212 patients with GD1 in the United States found that over 50\% of those who received medical attention were diagnosed in childhood or adolescence [18].

In childhood and adolescence, presenting symptoms of GD1 are primarily hematological, leading to frequent misdiagnosis of GD1 as a hematological/oncological disorder [19]. These symptoms may include anemia, thrombocytopenia, nosebleeds, excessive bleeding, and splenomegaly [18]. Splenomegaly is present in about $95 \%$ of children diagnosed with GD and usually appears prior to other manifestations $[6,20]$.

GD3 may present in childhood with splenomegaly, anemia, thrombocytopenia, bone crises, or kyphosis, along with neurological manifestations. In a rare subset of patients with GD3, severe cardiac valve involvement may develop. The diagnosis of GD3 is frequently made by a neuro-ophthalmologist when abnormal eye movements are noted [21].

It is recommended that treatment begin early in symptomatic children with GD1 and GD3 to avoid irreversible bony and visceral damage as well as other long-term growth and development issues [22]. Short stature or growth retardation is prevalent in patients with both GD1 and GD3 [6,23]. Prior to development of ERT, patients with severe phenotypes of GD often experienced a delay of puberty. When treated, these children had a normalized onset of puberty and a corrected growth curve, both in stature and lean muscle mass [3,24]. However, even treated patients may not reach a full expected height [25].

Bone manifestations in GD, which typically appear in adolescence, are varied and can include osteonecrosis, bone pain crises, lytic lesions, osteoporosis (across the lifespan), pathological fractures, and the Erlenmeyer flask deformity. In one study, this characteristic deformity was present in $63 \%$ of patients who presented with GD prior to age 10 [23]. Additionally, altered bone density is most pronounced during and after adolescence [26]. Decreases in bone density during this time of bone maturation lead to a decrease in overall peak bone mass. Even in asymptomatic patients with normal bone marrow density, there may be underlying disruption of the bone's trabecular architecture, causing a decrease in bone stability [27]. While the basis of the bone pathology observed in GD is still only partially understood, it is estimated that up to $75-90 \%$ of patients diagnosed with GD will experience some bone findings throughout the course of their disease [26,28]. Treatment during adolescence, when needed, may ameliorate some of these affects, increasing bone health and stability later in life [26].

\subsubsection{Neurological manifestations in childhood and adolescence-}

Neurological manifestations are a hallmark of GD3 and can present in childhood, 
adolescence, or even adulthood [29]. The most common manifestation is horizontal supranuclear gaze palsy, and in some individuals, this is the only neurological symptom [14]. These eye movement abnormalities are characterized by a slowing, looping, or absence of the horizontal saccades. Vertical saccades may also be affected to a lesser degree [21,30]. Some individuals develop additional neurological manifestations including seizures, myoclonus, and progressive myoclonic epilepsy. Electroencephalography can reveal generalized background slowing or epileptiform discharges [21,31]. Abnormal brainstem auditory evoked potentials in addition to abnormal somatosensory evoked potentials have also been noted in some individuals [32,33]. The range of neurological manifestations is broad and the severity varies greatly. Some individuals exhibit intelligence quotients (IQs) well below average, with several learning and functional deficits, while others have IQs in the superior range and complete college and advanced degrees [21,31,34]. The performance IQ is typically lower than the verbal IQ, suggesting a visual-spatial deficit visuospatial deficit that may be related to eye movement or other motor issues. This disparity is inconsistent with what is seen in age-matched controls and persists across all ranges of the IQ scale [31,34]. The neurological manifestations appear resistant to ERT and can worsen with disease progression [35]. However, it is important to note that decline is not seen in all individuals, and some improve over time [31].

\section{Diagnosis and symptomatic presentations in adulthood}

Symptoms presenting in adulthood are often similar to those in childhood and include anemia, thrombocytopenia, hepatosplenomegaly, and bone manifestations. In general, patients who only develop symptoms in adulthood are considered to have milder GD, but there are exceptions.

Women may present with an exacerbation of GD symptoms around menarche or initially notice heavier bleeding during their menstrual cycles [36]. Pregnancy can exacerbate GD, and bleeding complications in pregnancy frequently lead to diagnosis in adulthood. Normal pregnancy outcomes are reported in both symptomatic treated and asymptomatic untreated patients with GD [37]. Currently, the recommendations for pregnancy are that asymptomatic patients should not begin therapy unless necessary, and symptomatic-treated patients should continue ERT, as its safety has been established during pregnancy. Substrate reduction therapy (SRT) should be discontinued, as it could cause fetal harm [38]. There are no indications that GD affects fertility [39].

Other adult manifestations of GD may include pulmonary fibrosis and pulmonary hypertension. The prevalence of subclinical pulmonary hypertension is not well established, but is relatively rare. It may become life threatening, especially in patients who have undergone a splenectomy [40]. ERT has been shown to decrease pulmonary hypertension but does not affect the fibrotic changes that have already occurred [41]. Gallstones are also seen with an increased frequency in adults with GD [42].

\subsection{Patients with malignancies}

During the pre-ERT era, autopsy studies demonstrated that cancers contributed frequently to premature death in patients with GD [43]. Currently, multiple myeloma appears to be the 
most commonly linked malignancy, with a relative risk range of 37.5-51.5 in longitudinal studies [44-46]. Furthermore, a recent study demonstrated that clonal immunoglobulin in 17 of 20 patients with GD, as well as 6 of $6 \mathrm{gba}^{-/-}$mice, with monoclonal gammopathy was reactive against glucoslysphingosine (LGL1) [47]. Other hematological malignancies are implicated with GD at a relative risk as high as $12.7[45,48,49]$. Moreover, cases of rare malignancies such as ovarian dysgerminoma and neuroblastoma have been reported in patients with GD [50,51]. Many cancer therapeutic investigations have focused on the glycosphingolipid pathway, with particular interest in ceramide, one product of the hydrolysis of glucosylceramide by GCase, because of its proapoptotic and anticancer properties [52]. Conversely, sphingosine-1-phosphate, another reactive biolipid that is a product of glycosphingolipid metabolism, has been shown to have promitogenic, antiapoptotic, and pro-angiogenic properties [53]. In a mouse model of GD that develops myeloma, SRT administration with eliglustat tartrate reduced glucosylsphingosine levels and prevented the development of myelomas [47,54]. However, it is still unclear whether ERT and SRT impact the frequency of malignancies in patients with GD.

\subsection{Parkinsonism and GD}

Interest in $G B A 1$, and GD research in general, has increased markedly since the connection was established between GD and the more common disorder, Parkinson disease (PD) [55]. A multicenter study of 5691 patients with PD and 4898 healthy controls demonstrated that patients with PD have an odds ratio of 5.43 for carrying a $G B A 1$ mutation [56]. Furthermore, heterozygous mutations in $G B A 1$ are the most common known genetic risk factor for PD and associated Lewy body disorders. In one study, $25 \%$ of patients with GD had a first-degree relative who was a carrier for GD and developed parkinsonism [57]. Many movement disorder centers now screen their patients for $G B A 1$ mutations, and they have identified both patients and carriers of GD.

GBA1-associated parkinsonian manifestations often resemble those of sporadic PD with good response to levadopa. Some studies show an earlier age of onset of parkinsonian symptoms, greater cognitive deficits, and a more rapid progression of motor impairment in $G B A 1$-associated PD [56]. In some individuals, manifestations can more closely reflect features of dementia with Lewy bodies (DLB) [58]. Still, symptoms and progression can vary greatly.

Studies investigating the molecular cause of GBA1-PD have focused on the inverse relationship between GCase levels and a-synuclein [59-61], the protein aggregated in Lewy bodies. Two predominating hypotheses have been proposed. The gain-of-function hypothesis states that $a$-synuclein accumulates and aggregates with misfolded GCase. However, null alleles in $G B A 1$ are associated with an even higher risk of developing PD [62]. Since the gain-of-function hypothesis depends on simultaneous mutant, misfolded GCase, and asynuclein accumulation, the observation that null alleles are also associated with a higher risk of PD refutes this hypothesis. On the other hand, the loss-of-function hypothesis states that loss of GCase activity would result in substrate accumulation and change in a-synuclein homeostasis. However, the fact that most patients with GD do not develop PD suggests that low levels of GCase alone are insufficient to cause PD. 


\section{The challenges in predicting clinical phenotype}

Understanding the basis for the phenotypic variation in GD has proven to be challenging at all points throughout the lifetime. Neither the amount of residual enzymatic activity [63], nor the quantity of lipid stored [64], has correlated well with the patient phenotype. In the age of molecular diagnostics, there was considerable hope that the genotype might be used to predict the clinical course. To date, researchers have identified over 400 different mutations in GBA1 in patients with GD, [65] but phenotypic implications of these mutations are not always clear. For example, siblings who share the same mutations can have different symptoms, responses to treatment, and disease courses. This has stimulated research to identify genetic modifiers that may impact Gaucher pheno-types. Among the modifier genes proposed for $G B A 1$ are $C L N 8$ [66], GRIN2b [67], and PGRN [68].

Despite the lack of clear correlations, there are several mutations that are associated with neuronopathic and non-neuronopathic illness. The L444P allele has been encountered in all three types of GD, although homozygotes generally have GD3 and many have no progressive neurodegeneration [65]. L444P homozygotes are common among all ethnicities, and pheno-types can range from highly successful college graduates to children with severe autism [63], indicating the contribution of genetic modifiers. R463C is another mutation frequently seen with GD3, often accompanied by an L444P, null, or recombinant mutation on the second allele. Among patients with GD3 and myoclonic epilepsy, mutations V394L, G377S, and N188S are frequently found. D409H homozygotes have a unique cardiac phenotype which can include cardiac valve abnormalities, cor-neal opacities, and, at times, hydrocephalus [69].

Many genotypes are associated with GD2, including some rare mutations specific to individual families and others that are more common. An L444P allele might be seen in combination with a recombinant allele that includes L444P (L444P/rec), though true homozygosity for L444P is rarely associated with GD2. Homozygosity for a null allele, or a recombinant allele encompassing large segments of the $G B A 1$ pseudogene, is associated with neonatal lethality [16].

In the United States, Europe, and Israel, the majority of patients presenting after the second decade have at least one N370S allele, and the frequency of new patients who are N370S homozygotes increases as the population ages [23]. N370S homozygosity is solely associated with non-neuronopathic GD although it is seen in patients with PD [70]. The N370S allele is the most common mutation in the Ashkenazi Jewish population and is often associated with milder visceral disease, especially in the homozygous state. However, even among N370S homozygotes, symptoms vary, specifically the presence and severity of bone disease [71]. Avascular necrosis, especially of the hip, and other bone infarcts, can have debilitating effect on joints, leading to a need for joint replacement $[72,73]$.

While these genotype associations are helpful in some cases, there are still many instances where no clear phenotypic predictions can be made. Overlap in phenotype can occur throughout the entire lifetime and makes definitive diagnosis and prediction of disease progression difficult. During infancy and early in the disease course, saccadic eye 
movements and other diagnostic measures often cannot be assessed accurately. With an ambiguous genotype, it may be difficult to distinguish between a child with severe GD1 and a child with milder GD3 (Figure 1). Additionally, the distinction between GD2 and GD3 is not always clear. Goker-Alpan et al. [74] described a series of children with an intermediate phenotype who were diagnosed in the first year of life and lived from 2 to 8 years. These children attained some developmental milestones, including walking and talking, but ultimately succumbed to neurological disease during the first decade of life [74].

Distinguishing between disease subtypes is essential, as symptomatic infants with GD1 or GD3 should begin ERT as soon as possible. Studies completed by the International Gaucher Registry demonstrated that pediatric patients with GD3 show great improvement after treatment with ERT. Amelioration of most hematological and visceral symptoms is seen in under 12 months, with stabilization of all non-neurological parameters within 5 years [75]. Because ERT does not affect the neurological symptoms or progression of the disease, treatment for GD2 is controversial, and management is generally supportive or palliative. As such, there is a great need for methods to distinguish between the different phenotypes during young ages. Skin biopsies performed for specific electron microscopy structural studies may be used to discriminate GD2 from GD3. In a series of 25 skin biopsies from individuals with GD, 20 babies (100\%) with GD2 were found to have uniquely disrupted epidermal ultrastructure [76]. However, this evaluation is not readily available.

On the other end of the age spectrum, many questions have been raised regarding genotypephenotype associations and the impact of genotype on the development of parkinsonism and dementia. Some studies suggest differential degrees of cognitive decline based upon the 'severity' of $G B A 1$ mutations $[62,77]$. However, polymorphisms in $G B A 1$ that do not cause GD, such as E326K and T369M, are common in patients with parkinsonism [78,79], as are mild mutations like N370S. Gary et al. [80] suggest that because N370S is the most frequent GBA1 allele in patients with DLB [81-83], 'severity' of the genotype alone cannot account for the degree of cognitive decline [80]. As $G B A 1$ receives increased attention in the movement disorders community, it is likely that genetic modifiers will reveal the basis for some of this variability.

Understanding the relationship of common mutations to different phenotypes presenting throughout the entire lifespan is important for patient counseling and treatment. New assays or biomarkers may provide additional information to inform phenotypic predictions.

\section{Biomarkers of disease severity and therapeutic efficacy}

Objective measures that reflect disease severity and can be evaluated as therapeutic outcomes are necessary for assessing GD and developing a treatment strategy. This may be increasingly important as more patients are diagnosed pre-symptomatically through different screening programs.

Chitotriosidase has been employed as a biomarker for over a decade, but some patients have an inherited deficiency of this enzyme [84,85]. Currently, LysoGb1 appears to be the most sensitive and predictive biomarker of GD symptoms such as thrombocytopenia and 
splenomegaly [86,87]. Other potential molecular biomarkers include low-density lipoprotein [88], osteoactivin [89], serum ferritin [90], progranulin [91], and CCL18 [85,92,93]. Imaging modalities such as magnetic resonance imaging [94,95], dual energy $\mathrm{X}$-ray absorptiometry [24], Fourier transform infrared spectroscopy [96], and transient and shearwave elastography [97] have also been employed to study key features of GD. However, further studies are necessary to establish the efficacy of these imaging methodologies.

To date, there is no gold standard biomarker that can confidently predict the key features of GD. While many potential biomarkers have been identified, each has inherent limitations; so, clinical parameters continue to define treatment goals and assess outcomes.

\section{Therapeutic treatment goals for GD}

The European Working Group on GD separates treatment goals into short- and long-term categories [98] (Table 1). This model includes fatigue, quality of life, and prevention of additional long-term sequelae not addressed in earlier guidelines. This more holistic view highlights a deeper understanding of the long-term impact of GD and establishes standard outcomes in treated patients across all therapeutic modalities.

\subsection{Therapeutic management of GD}

Historically, GD1 was treated with supportive measures such as splenectomy and orthopedic procedures. Today, new therapeutics have dramatically altered the natural history of the disease both in children and adults. Approved therapies include ERT and SRT (Box 2); other therapeutic strategies are currently in development.

6.1.1. ERT-ERT has revolutionized the treatment of GD and has markedly improved the prognoses of patients with GD1 and GD3. The concept of treating GD with ERT was first introduced by Brady [99] and was implemented clinically in 1991 as a US FDA-approved therapy for patients with GD1 and later, GD3 [100]. Placenta-derived alglucersae (Ceredase $^{\mathrm{TM}}$, Genzyme) was the first ERT employed to treat GD. The infused enzyme was sequentially deglycosylated to expose specific glycoforms in an attempt to better target ERT to affected macrophages [101].

Alglucerase was replaced by human recombinant imiglucerase (Cerezyme ${ }^{\mathrm{TM}}$, Sanofi/ Genzyme) in the mid-1990s and continues to be the most widely used ERT in clinics across the world. In 2009, a vesivirus 2117 infection of the bioreactors in which imiglucerase was manufactured led to a global shortage of imiglucerase and expedited the approval of two 'new' enzymes: gene-activated human recombinant velaglucerase alfa (VPRIV ${ }^{\mathrm{TM}}$, Shire) and plant cell-derived human recombinant taliglucerase alfa (Elelyso ${ }^{\mathrm{TM}}$ Protalix/Pfizer).

Although these three ERTs are not biosimilars, there appears to be no difference in safety between them [102-104].

In terms of efficacy, when administered prior to irreversible skeletal manifestations, most patients do extremely well, with correction of disease parameters. While dosage varies depending on the country and health of the individual, the recommended starting doses are $60 \mathrm{U} / \mathrm{kg}$ every other week for children and 30-60 U/kg every other week for adults [105]. 
Dose reduction is reserved for individuals who have met therapeutic goals and therefore have 'stable GD1' [106]. Some reports have decreased the dosage to $30 \mathrm{U} / \mathrm{kg} / \mathrm{month}$ and demonstrated positive visceral and hematological outcomes [107,108]. Doses below $15 \mathrm{U} / \mathrm{kg}$ every other week (30 U/kg/month), however, have failed to prevent painful bone crises in some patients $[109,110]$.

Although ERT dramatically improves the systemic symptoms of GD, virtually eliminating splenectomy as a treatment, neurological manifestations are not impacted by available therapies. Despite this, ERT has improved the quality of life of those with GD in many ways. For example, after years of ERT, some patients with GD are often able to take 'drug holidays,' or temporary delays in enzyme administration of up to a few months, without redevelopment of symptoms [111]. Early administration of ERT has also been shown to positively impact the growth of children [25,112]. Furthermore, ERT has been shown to decrease bleeding during pregnancy, delivery, and postpartum and improves overall outcomes of mothers who have suffered previous miscarriages [38].

Substantial efforts have been made to improve clinical recognition of GD and to initiate early treatment. However, Mehta and colleagues [18] recently reported that one in six patients with GD experience a delay in treatment initiation of 7 years or more, following their first physician consultation presenting with hallmark GD symptoms [18]. To further compound the delay in treatment, there continues to be a disparity in ERT availability and affordability worldwide. This has led to children with GD1 who, despite the proven efficacy of the enzyme, are unable to afford or gain access to ERT and die due to GD-related complications [113].

6.1.2. SRT-SRT is an alternate treatment strategy first proposed by Radin [114]. While ERT aims to rectify the absence and/or inactivity of GCase, SRT decreases glucocerebroside (GlcCer) production, making residual GCase activity sufficient to cleave the remaining lysosomal GlcCer. SRT was predicted to be more appealing to patients because it is administered orally, unlike ERT. Additionally, it was predicted to cost less, act on tissues not affected by ERT, and avoid potential immune responses that may be associated with infused proteins [115].

Miglustat (N-butyldeoxynojirimycin; Zavesca ${ }^{\mathrm{TM}}$, Actelion) was the first SRT approved by the FDA and EMA in 2002. Although miglustat improved several hallmark features of GD, including hemoglobin concentrations, platelet counts, hepatosplenomegaly, and bone density [116-119], several adverse effects were reported. These included diarrhea, weight loss, tremor, and peripheral neuropathy. As a result, 49 of 115 patients discontinued use of miglustat after experiencing such side effects [120-122].

A newly developed SRT, eliglustat tartrate (Cerdelga ${ }^{\mathrm{TM}}$, Sanofi/Genzyme), was approved in 2014. Eliglustat is administered to CYP2D6 extensive, intermediate, or poor metabolizers since it is eliminated via the CYP2D6 pathway. The recommended dosage of eliglustat is lower in poor metabolizers, and use is contraindicated in patients who are ultrarapid metabolizers due to difficulty obtaining reliable blood levels of the drug [65]. Although eliglustat is currently used as a first-line therapeutic, it is necessary to continue to compare 
eliglustat's performance against ERT using consistent parameters and nomenclature [123], as there has been a lack of clarity when comparing results from ERT and eliglustat trials [124]. Concerns regarding lack of long-term safety data, in addition to high annual costs, have led many individuals to continue ERT, rather than switch to SRT. New forms of SRT engineered to cross the BBB are currently being developed and tested.

6.1.3. Pharmacological chaperones-Though not currently approved for clinical use, pharmacological chaperones have been the subject of intense investigation due to their ability to pass through the BBB, potentially ameliorating the neuronopathic features of GD2 and GD3. Small molecule chaperones decrease the amount of GCase retained in the endoplasmic reticulum (ER) by facilitating proper GCase folding and translocation to the lysosome. This reduces physiological stress on the ER and ER-associated GCase degradation, increasing lysosomal levels of GCase.

The first chaperone administered to patients with GD was afegostat tartrate (Plicera ${ }^{\mathrm{TM}}$ Amicus Therapeutics) [125]. In a phase 2 randomized, open-label study to assess the safety, tolerability, and preliminary efficacy in treatment-naive adult patients with GD1, results were disappointing [126]. Another chaperone, ambroxol, is a pH-dependent mixed inhibitor of GCase, which appears to facilitate translocation in cellular and mouse models; a human study is underway [127-129]. In a small, non-randomized study by Narita and colleagues [129], ambroxol combined with ERT was shown to cross the BBB, increase GCase activity in lymphocytes, and positively impact patients with myoclonic epilepsy. However, the efficacy of inhibitory active-site chaperones like ambroxol and afegostat tartrate may be limited because they must out-compete GlcCer at its active site to facilitate folding and translocation of GCase.

Non-inhibitory chaperones, which bind to a site distant from the active site, offer some advantages. They do not need to outcompete GlcCer to act upon GCase, and binding to GCase can be 'programmed' to release the chaperone once GCase is delivered to the lysosome. This frees GCase to cleave its glycolipid substrates. Two such chaperones have been identified. In primary macrophages, differentiated from patient-derived monocytes and induced pluripotent stem cells (iPSCs), these chaperones increased GCase activity, decreased substrate accumulation, and restored chemotaxis [130]. In iPSC-derived dopaminergic neurons, the same chaperones increased GCase activity, decreased substrate storage, and lowered levels of a-synuclein [131]. These results suggest that non-inhibitory chaperones are promising drug candidates and might prove useful in patients with GBA1associated parkinsonism, as long as there is residual GCase activity. However, development of new non-inhibitory chaperones has been slow due to lack of GCase-specific fluorescentbased substrates that can measure the GCase activity in the lysosomes [132].

Ultimately, the optimal therapeutic strategy may include a combination of therapies. ERT may be useful to initiate the 'debulking' of diseased cells in patients with significant clinical disease burden. Subsequently, or in less-affected patients, SRT or chaperones may be able to prevent re-accumulation of the substrate. Combining ERT with chaperone therapy may lower the required dose and subsequent cost. 


\section{Conclusions}

The clinical features of GD have changed drastically due to early screening and the administration of ERT. Although there have been significant improvements to the disease prognosis since ERT was first approved over 25 years ago, there are still many unmet challenges (Box 3). There is an urgent need for less costly therapies, as well as treatments that ameliorate the neurological manifestations seen in patients with GD2 and GD3. Improved diagnostics are needed to facilitate earlier treatment, and reliable biomarkers are needed to assess the efficacy of new therapies. Next-generation sequencing and genotype/ phenotype studies may identify potential biomarkers and uncover other factors contributing to the clinical variation encountered in this disorder. These studies may also improve our understanding of the link between GD and PD, as well as GD and multiple myeloma, and will likely inform our understanding of the pathogenesis of these diseases.

\subsection{Expert commentary}

The spectrum of phenotypes associated with GD continues to expand. The number of children without symptoms identified through screening programs is dramatically increasing, providing new challenges for clinicians in predicting outcomes. While genotypic assessments can be helpful, clearly, there are other factors impacting disease phenotype. Detecting symptomatic GD in very young patients is essential for disease management and genetic counseling. While early intervention provides great benefit in symptomatic children with GD1 and GD3, palliative care might be considered early on for those with GD2. Identifying the different factors that impact disease phenotype will likely provide new insights into disease pathogenesis.

Today, there are several effective therapeutic options for patients with GD. Children can be treated with the various forms of ERT, and adults have the option of ERT or SRT. Both are life-long, extremely costly treatments and thus not available in all parts of the world. New therapies, and combinations of therapies, are in different stages of development and will require further evaluation. Other remaining challenges are treatments for neuronopathic GD, understanding inflammatory and parkinsonian phenotypes, and establishing the optimal time to intervene in specific patients.

\subsection{Five-year view}

- We anticipate new advances in our ability to diagnose and treat GD, as the association with parkinsonism is greatly increasing attention to this rare disorder.

- $\quad$ Newborn screening and next-generation whole-exome or whole-genome sequencing are with likely to identify more cases of GD, broadening the phenotypic spectrum even more.

- Genetic and epigenetic modifiers that impact phenotype are likely to be discovered. These factors may improve our ability to make phenotypic predictions and identify new biomarkers.

- Development of small molecule drugs that can cross the BBB and impact neuronopathic GD will continue. 
- $\quad$ Combinations of therapeutic modalities for specific patients will be considered.

- $\quad$ An improved understanding of the role of GCase in PD pathogenesis could lead to new treatments for early parkinsonism.

\title{
Acknowledgments
}

\author{
Funding \\ This work was supported by the Intramural Research Programs of the National Human Genome Research Institute \\ and the National Institutes of Health
}

\section{References}

Papers of special note have been highlighted as either of interest $(\bullet)$ or of considerable interest $(\bullet)$ to readers.

1. Nalysnyk L, Rotella P, Simeone JC, et al. Gaucher disease epidemiology and natural history: a comprehensive review of the literature. Hematology. 2017;22(2):65-73. [PubMed: 27762169]

2. Sidransky E, Tsuji S, Stubblefield BK, et al. Gaucher patients with oculomotor abnormalities do not have a unique genotype. Clin Genet. 1992;41(1):1-5. [PubMed: 1633639]

3. Elstein D, Altarescu G, Abrahamov A, et al. Children with type 1 Gaucher disease: changing profiles in the 21st century. Blood Cells Mol Dis. 2016;68:93-96. [PubMed: 28185830]

4. Burton BK, Charrow J, Hoganson GE, et al. Newborn screening for lysosomal storage disorders in illinois: the initial 15-month experience. J Pediatr. 2017;190:130-135. [PubMed: 28728811]

5. Hopkins PV, Campbell C, Klug T, et al. Lysosomal storage disorder screening implementation: findings from the first six months of full population pilot testing in Missouri. J Pediatr. 2015;166(1): 172-177. [PubMed: 25444528]

6. Andrade-Campos M, Alfonso P, Irun P, et al. Diagnosis features of pediatric Gaucher disease patients in the era of enzymatic therapy, a national-base study from the Spanish registry of Gaucher disease. Orphanet J Rare Dis. 2017;12(1):84. [PubMed: 28468677]

7. Yang AC, Bier L, Overbey JR, et al. Early manifestations of type 1 Gaucher disease in presymptomatic children diagnosed after parental carrier screening. Genet Med off J Am Coll Med Genet. 2017;19(6):652-658. First description of children diagnosed through screening.

8. Mignot C, Gelot A, Bessieres B, et al. Perinatal-lethal Gaucher disease. Am J Med Genet A. 2003;120A(3):338-344. [PubMed: 12838552]

9. Bruwer Z, Al Riyami N, Al Dughaishi T, et al. Inborn errors of metabolism in a cohort of pregnancies with non-immune hydrops fetalis: a single center experience. J Perinat Med. 2017. doi: 10.1515/jpm-2017-0124

10. Bellini C, Donarini G, Paladini D, et al. Etiology of non-immune hydrops fetalis: an update. Am J Med Genet A. 2015;167A (5):1082-1088. [PubMed: 25712632]

11. Stone DL, Sidransky E. Hydrops fetalis: lysosomal storage disorders in extremis. Adv Pediatr. 1999;46:409-440. [PubMed: 10645471]

12. Staretz-Chacham O, Lang TC, LaMarca ME, et al. Lysosomal storage disorders in the newborn. Pediatrics. 2009;123(4):1191-1207. [PubMed: 19336380]

13. Carr PC, Casamiquela KM, Jacks SK. Gaucher disease Type 2 presenting with collodion membrane and blueberry muffin lesions. Pediatr Dermatol. 2016;33(1):e20-22. [PubMed: 26646163]

14. Roshan Lal T, Sidransky E. The spectrum of neurological manifestations associated with Gaucher disease. Diseases. 2017;5:1.

15. Gupta N, Oppenheim IM, Kauvar EF, et al. Type 2 Gaucher disease: phenotypic variation and genotypic heterogeneity. Blood Cells Mol Dis. 2011;46(1):75-84. [PubMed: 20880730] 
16. Weiss K, Gonzalez A, Lopez G, et al. The clinical management of type 2 Gaucher disease. Mol Genet Metab. 2015;114(2):110-122. [PubMed: 25435509] • Describes key features and management of GD2.

17. Wolf P, Alcalay RN, Liong C, et al. Tandem mass spectrometry assay of beta-glucocerebrosidase activity in dried blood spots eliminates false positives detected in fluorescence assay. Mol Genet Metab. 2018;123(2):135-139. [PubMed: 29100779]

18. Mehta A, Belmatoug N, Bembi B, et al. Exploring the patient journey to diagnosis of Gaucher disease from the perspective of 212 patients with Gaucher disease and 16 Gaucher expert physicians. Mol Genet Metab. 2017;122(3):122-129. [PubMed: 28847676]

19. Di Rocco M, Andria G, Deodato F, et al. Early diagnosis of Gaucher disease in pediatric patients: proposal for a diagnostic algorithm. Pediatr Blood Cancer. 2014;61(11):1905-1909. [PubMed: 25131373]

20. Kaplan P, Andersson HC, Kacena KA, et al. The clinical and demographic characteristics of nonneuronopathic Gaucher disease in 887 children at diagnosis. Arch Pediatr Adolesc Med. 2006;160(6):603-608. [PubMed: 16754822]

21. Benko W, Ries M, Wiggs EA, et al. The saccadic and neurological deficits in type 3 Gaucher disease. PLoS One. 2011;6(7):e22410. [PubMed: 21799847]

22. Baldellou A, Andria G, Campbell PE, et al. Paediatric non-neuronopathic Gaucher disease: recommendations for treatment and monitoring. Eur J Pediatr. 2004;163(2):67-75. [PubMed: 14677062]

23. Grabowski GA, Zimran A, Ida H. Gaucher disease types 1 and 3: phenotypic characterization of large populations from the ICGG Gaucher Registry. Am J Hematol. 2015;90(Suppl 1):S12-18. [PubMed: 26096741]

24. Dar L, Tiomkin M, Elstein D, et al. Bone mineral density and lean muscle mass characteristics in children with Gaucher disease treated with enzyme replacement therapy or untreated. Blood Cells Mol Dis. 2018;68:135-138. [PubMed: 27847274]

25. Mendelsohn E, Meir A, Abrahamov A, et al. Growth and final height of children with Gaucher disease: a 15-year follow-up at an Israeli Gaucher center. Blood Cells Mol Dis. 2018;68:97-99. [PubMed: 27993449]

26. Mistry PK, Weinreb NJ, Kaplan P, et al. Osteopenia in Gaucher disease develops early in life: response to imiglucerase enzyme therapy in children, adolescents and adults. Blood Cells Mol Dis. 2011;46(1):66-72. [PubMed: 21112800]

27. Baldini M, Casirati G, Ulivieri FM, et al. Skeletal involvement in type 1 Gaucher disease: not just bone mineral density. Blood Cells Mol Dis. 2017;68:148-152. [PubMed: 28693786]

28. Drelichman G, Fernandez Escobar N, Basack N, et al. Skeletal involvement in Gaucher disease: an observational multicenter study of prognostic factors in the Argentine Gaucher disease patients. Am J Hematol. 2016;91(10):E448-453. [PubMed: 27420181]

29. Guimarães J, Amaral O, Sá Miranda MC. Adult-onset neuronopathic form of Gaucher's disease: a case report. Parkinsonism Relat Disord. 2003;9(5):261-264. [PubMed: 12781591]

30. Park JK, Orvisky E, Tayebi N, et al. Myoclonic epilepsy in Gaucher disease: genotype-phenotype insights from a rare patient subgroup. Pediatr Res. 2003;53(3):387-395. [PubMed: 12595585]

31. Altarescu G, Hill S, Wiggs E, et al. The efficacy of enzyme replacement therapy in patients with chronic neuronopathic Gaucher's disease. J Pediatr. 2001;138(4):539-547. [PubMed: 11295718]

32. Garvey MA, Toro C, Goldstein S, et al. Somatosensory evoked potentials as a marker of disease burden in type 3 Gaucher disease. Neurology. 2001;56:391-394. [PubMed: 11171908]

33. Tantawy AA, Sherif EM, Adly AA, et al. Evoked potentials and neurocognitive functions in pediatric Egyptian Gaucher patients on enzyme replacement therapy: a single center experience. $\mathrm{J}$ Inherit Metab Dis. 2013;36(6):1025-1037. [PubMed: 23508695]

34. Goker-Alpan O, Wiggs EA, Eblan MJ, et al. Cognitive outcome in treated patients with chronic neuronopathic Gaucher disease. J Pediatr. 2008;153(1):89-94. [PubMed: 18571543]

35. Campbell PE, Harris CM, Vellodi A. Deterioration of the auditory brainstem response in children with type 3 Gaucher disease. Neurology. 2004;63:385-387. [PubMed: 15277647] 
36. Zimran A, Morris E, Mengel E, et al. The female Gaucher patient: the impact of enzyme replacement therapy around key reproductive events (menstruation, pregnancy and menopause). Blood Cells Mol Dis. 2009;43(3):264-288. [PubMed: 19502088]

37. Lau H, Belmatoug N, Deegan P, et al. Reported outcomes of 453 pregnancies in patients with Gaucher disease: an analysis from the Gaucher outcome survey. Blood Cells Mol Dis. 2018;68:226-231. [PubMed: 27839985]

38. Granovsky-Grisaru S, Belmatoug N, vom Dahl S, et al. The management of pregnancy in Gaucher disease. Eur J Obstet Gynecol Reprod Biol. 2011;156:3-8. [PubMed: 21269752]

39. Rosenbaum H Management of women with Gaucher disease in the reproductive age. Thromb Res. 2015;135(Suppl 1):S49-51. [PubMed: 25903536]

40. Mistry PK, Sirrs S, Chan A, et al. Pulmonary hypertension in type 1 Gaucher's disease: genetic and epigenetic determinants of phenotype and response to therapy. Mol Genet Metab. 2002;77(1-2): 91-98. [PubMed: 12359135]

41. de Boer GM, van Dussen L, Van Den Toorn LM, et al. Lung transplantation in Gaucher disease: a learning lesson in trying to avoid both scylla and charybdis. Chest. 2016;149(1):e1-5. [PubMed: 26757299]

42. Rosenbaum H, Sidransky E. Cholelithiasis in patients with Gaucher disease. Blood Cells Mol Dis. 2002;28(1):21-27. [PubMed: 11987238]

43. Weinreb NJ, Lee RE. Causes of death due to hematological and non-hematological cancers in 57 US patients with type 1 Gaucher disease who were never treated with enzyme replacement therapy. Crit Rev Oncog. 2013;18(3):177-195. [PubMed: 23510063]

44. Rosenbloom BE, Weinreb NJ, Zimran A, et al. Gaucher disease and cancer incidence: a study from the Gaucher registry. Blood. 2005;105:4569-4572. [PubMed: 15718419]

45. de Fost M, vom Dahl S, Weverling GJ, et al. Increased incidence of cancer in adult Gaucher disease in Western Europe. Blood Cells Mol Dis. 2006;36(1):53-58. [PubMed: 16246599]

46. Taddei TH, Kacena KA, Yang M, et al. The underrecognized progressive nature of N370S Gaucher disease and assessment of cancer risk in 403 patients. Am J Hematol. 2009;84(4):208-214. [PubMed: 19260119]

47. Nair S, Branagan AR, Liu J, et al. Clonal immunoglobulin against lysolipids in the origin of myeloma. N Engl J Med. 2016;374(6):555-561. [PubMed: 26863356]

48. Arends M, van Dussen L, Biegstraaten M, et al. Malignancies and monoclonal gammopathy in Gaucher disease; a systematic review of the literature. Br J Haematol. 2013;161(6):832-842. [PubMed: 23594419]

49. Zimran A, Liphshitz I, Barchana M, et al. Incidence of malignancies among patients with type I Gaucher disease from a single referral clinic. Blood Cells Mol Dis. 2005;34(3):197-200. [PubMed: 15885601]

50. Madeo A, Garaventa A, Sementa AR, et al. The unusual association between neuroblastoma and Gaucher disease: case report and review of the literature. Blood Cells Mol Dis. 2018;68(Supplement C):106-108. [PubMed: 27908537]

51. Kojiro M, Kage M, Abe H, et al. Association of dysgerminoma and gaucher's disease. Cancer. 1983;51(4):712-715. [PubMed: 6821841]

52. Ogretmen B, Hannun YA. Biologically active sphingolipids in cancer pathogenesis and treatment. Nat Rev Cancer. 2004;4:604. [PubMed: 15286740]

53. Hannun YA, Obeid LM. Principles of bioactive lipid signalling: lessons from sphingolipids. Nat Rev Mol Biol. 2008;9:139.

54. Pavlova EV, Archer J, Wang S, et al. Inhibition of UDP-glucosylcer-amide synthase in mice prevents Gaucher disease-associated B-cell malignancy. J Pathol. 2015;235(1):113-124. [PubMed: 25256118]

55. Tayebi N, Walker J, Stubblefield B, et al. Gaucher disease with parkinsonian manifestations: does glucocerebrosidase deficiency contribute to a vulnerability to parkinsonism? Mol Genet Metab. 2003;79:104-109. [PubMed: 12809640]

56. Sidransky E, Nalls MA, Aasly JO, et al. Multicenter analysis of glucocerebrosidase mutations in Parkinson's disease. N Engl J Med. 2009;361:1651-1661. [PubMed: 19846850] •• Established the connection between GD and PD. 
57. Goker-Alpan O, Schiffmann R, LaMarca ME, et al. Parkinsonism among Gaucher disease carriers. J Med Genet. 2004;41:937-940. [PubMed: 15591280]

58. Lopez G, Kim J, Wiggs E, et al. Clinical course and prognosis in patients with Gaucher disease and parkinsonism. Neurol Genet. 2016;2(2):e57. [PubMed: 27123476]

59. Murphy KE, Gysbers AM, Abbott SK, et al. Reduced glucocerebrosidase is associated with increased a-synuclein in sporadic Parkinson's disease. Brain. 2014;137(3):834-848. [PubMed: 24477431]

60. Mazzulli JR, Xu YH, Sun Y, et al. Gaucher disease glucocerebrosidase and alpha-synuclein form a bidirectional pathogenic loop in synucleinopathies. Cell. 2011;146(1):37-52. [PubMed: 21700325]

61. Cullen V, Sardi SP, Ng J, et al. Acid beta-glucosidase mutants linked to Gaucher disease, Parkinson disease, and Lewy body dementia alter alpha-synuclein processing. Ann Neurol. 2011;69(6):940953. [PubMed: 21472771]

62. Gan-Or Z, Amshalom I, Kilarski LL, et al. Differential effects of severe vs mild GBA mutations on Parkinson disease. Neurology. 2015;84:880-887. [PubMed: 25653295]

63. Goker-Alpan O, Hruska KS, Orvisky E, et al. Divergent phenotypes in Gaucher disease implicate the role of modifiers. J Med Genet. 2005;42(6):e37. [PubMed: 15937077]

64. Orvisky E, Park JK, LaMarca ME, et al. Glucosylsphingosine accumulation in tissues from patients with Gaucher disease: correlation with phenotype and genotype. Mol Genet Metab. 2002;76(4): 262-270. [PubMed: 12208131]

65. Mistry PK, Lopez G, Schiffmann R, et al. Gaucher disease: progress and ongoing challenges. Mol Genet Metab. 2017;120:8-21. [PubMed: 27916601] •• Reviews current therapies and challenges for GD.

66. Zhang CK, Stein PB, Liu J, et al. Genome-wide association study of N370S homozygous Gaucher disease reveals the candidacy of CLN8 gene as a genetic modifier contributing to extreme phenotypic variation. Am J Hematol. 2012;87(4):377-383. [PubMed: 22388998]

67. Klein Andrés D, Ferreira N-S, Ben-Dor S, et al. Identification of modifier genes in a mouse model of Gaucher disease. Cell Rep. 2016;16(10):2546-2553. [PubMed: 27568557]

68. Jian J, Tian Q-Y, Hettinghouse A, et al. Progranulin recruits HSP70 to $\beta$-glucocerebrosidase and is therapeutic against Gaucher disease. EBioMedicine. 2016;13:212-224. [PubMed: 27789271]

69. George R, McMahon J, Lytle B, et al. Severe valvular and aortic arch calcification in a patient with Gaucher's disease homozygous for the D409H mutation. Clin Genet. 2001;59(5):360-363. [PubMed: 11359469]

70. Grabowski GA. Phenotype, diagnosis, and treatment of Gaucher's disease. Lancet (London, England). 2008;372(9645):1263-1271.

71. Mistry PK, Belmatoug N, vom Dahl S, et al. Understanding the natural history of Gaucher disease. Am J Hematol. 2015;90(Suppl 1):S6-11. [PubMed: 26096746]

72. Wenstrup RJ, Roca-Espiau M, Weinreb NJ, et al. Skeletal aspects of Gaucher disease: a review. $\mathrm{Br}$ J Radiol. 2002;75(Suppl 1):A2-12. [PubMed: 12036828]

73. Mikosch P Miscellaneous non-inflammatory musculoskeletal conditions. Gaucher disease and bone. Best Pract Res Clin Rheumatol. 2011;25(5):665-681. [PubMed: 22142746]

74. Goker-Alpan O, Schiffmann R, Park JK, et al. Phenotypic continuum in neuronopathic gaucher disease: an intermediate phenotype between type 2 and type 3. J Pediatr. 2003;143(2):273-276. [PubMed: 12970647]

75. El-Beshlawy A, Tylki-Szymanska A, Vellodi A, et al. Long-term hematological, visceral, and growth outcomes in children with Gaucher disease type 3 treated with imiglucerase in the international collaborative Gaucher group Gaucher registry. Mol Genet Metab. 2017;120(1):47-56. [PubMed: 28040394]

76. Chan A, Holleran W, Ferguson T, et al. Skin ultrastructural findings in type 2 Gaucher disease: diagnostic implications. Mol Genet Metab. 2011;104(4):631-636. [PubMed: 21982627]

77. Cilia R, Tunesi S, Marotta G, et al. Survival and dementia in GBA-associated Parkinson's disease: the mutation matters. Ann Neurol. 2016;80:662-673. [PubMed: 27632223]

78. Davis MY, Johnson CO, Leverenz JB, et al. Association of gba mutations and the e $326 \mathrm{k}$ polymorphism with motor and cognitive progression in parkinson disease. JAMA Neurol. 2016;73(10):1217-1224. [PubMed: 27571329] 
79. Mallett V, Ross JP, Alcalay RN, et al. GBA p.T369M substitution in Parkinson disease: polymorphism or association? A meta-analysis. Neurol Genet. 2016;2(5):e104. [PubMed: 27648471]

80. Gary SE, McMahon B, Lopez G, et al. Glucocerebrosidase mutations and parkinsonism: how much does the mutation matter? J Xiangya Med. 2018;3:1.

81. Nalls MA, Duran R, Lopez G, et al. A multicenter study of glucocerebrosidase mutations in dementia with Lewy bodies. JAMA Neurol. 2013;70:727. [PubMed: 23588557]

82. Shiner T, Mirelman A, Gana Weisz M, et al. High frequency of gba gene mutations in dementia with lewy bodies among ashkenazi jews. JAMA Neurol. 2016;73:1448-1453. [PubMed: 27723861]

83. Tsuang D, Leverenz JB, Lopez OL, et al. GBA mutations increase risk for Lewy body disease with and without Alzheimer disease pathology. Neurology. 2012;79:1944-1950. [PubMed: 23035075]

84. Boven LA, van Meurs M, Boot RG, et al. Gaucher cells demonstrate a distinct macrophage phenotype and resemble alternatively activated macrophages. Am J Clin Pathol. 2004;122:359_ 369. [PubMed: 15362365]

85. Hollak CE, van Weely S, Van Oers MH, et al. Marked elevation of plasma chitotriosidase activity. A novel hallmark of Gaucher disease. J Clin Investig. 1994;93:1288-1292. [PubMed: 8132768]

86. Dekker N, van Dussen L, Hollak CEM, et al. Elevated plasma glucosylsphingosine in Gaucher disease: relation to phenotype, storage cell markers, and therapeutic response. Blood. 2011;118:e118-e127. [PubMed: 21868580]

87. Rolfs A, Giese A-K, Grittner U, et al. Glucosylsphingosine is a highly sensitive and specific biomarker for primary diagnostic and follow-up monitoring in Gaucher disease in a non-Jewish. Caucasian Cohort Gaucher Disease Patients PLoS ONE. 2013;8:e79732. [PubMed: 24278166]

88. Watad S, Abu-Saleh N, Yousif A, et al. The role of high density lipoprotein in type 1 Gaucher disease. Blood Cells Mol Dis. 2018;68:43-46. [PubMed: 27876360]

89. Murugesan V, Liu J, Yang R, et al. Validating glycoprotein nonmetastatic melanoma B (gpNMB, osteoactivin), a new biomarker of Gaucher disease. Blood Cells Mol Dis. 2018;68:47-53. [PubMed: 28003098]

90. Lorenz F, Pawłowicz E, Klimkowska M, et al. Ferritinemia and serum inflammatory cytokines in Swedish adults with Gaucher disease type 1. Blood Cells Mol Dis. 2018;68:35-42. [PubMed: 27816428]

91. Jian J, Hettinghouse A, C-J L. Progranulin acts as a shared chaperone and regulates multiple lysosomal enzymes. Genes \& Dis 2017;4(3):125-126.

92. Boot RG, Verhoek M, De Fost M, et al. Marked elevation of the chemokine CCL18/PARC in Gaucher disease: a novel surrogate marker for assessing therapeutic intervention. Blood. 2004;103:33-39. [PubMed: 12969956]

93. Deegan PB, Moran MT, McFarlane I, et al. Clinical evaluation of chemokine and enzymatic biomarkers of Gaucher disease. Blood Cells Mol Dis. 2005;35:259-267. [PubMed: 16125420]

94. van Dussen L, Akkerman EM, Hollak CEM, et al. Evaluation of an imaging biomarker, dixon quantitative chemical shift imaging, in Gaucher disease: lessons learned. J Inherit Metab Dis. 2014;37:1003-1011. [PubMed: 24924293]

95. Maas M, van Kuijk C, Stoker J, et al. Quantification of bone involvement in Gaucher disease: MR imaging bone marrow burden score as an alternative to dixon quantitative chemical shift MR imaging —initial experience. Radiology. 2003;229:554-561. [PubMed: 14526090]

96. Igci N, Sharafi P, Demiralp DO, et al. Application of Fourier transform infrared spectroscopy to biomolecular profiling of cultured fibroblast cells from Gaucher disease patients: A preliminary investigation. Advances Clinical Experimental Medicine: Official Organ Wroclaw Medical University. 2017;26:1053-1061.

97. Webb M, Zimran A, Dinur T, et al. Are transient and shear wave elastography useful tools in Gaucher disease? Blood Cells Mol Dis. 2018;68:143-147. [PubMed: 28063644]

98. Biegstraaten M, Cox TM, Belmatoug N, et al. Management goals for type 1 Gaucher disease: an expert consensus document from the European working group on Gaucher disease. Blood Cells Mol Dis. 2018;68(Supplement C):203-208. Introduces new management guidelines for GD1. 
99. Brady RO, Kanfer JN, Bradley RM, et al. Demonstration of a deficiency of glucocerebrosidecleaving enzyme in Gaucher's disease. J Clin Investig. 1966;45(7):1112-1115. [PubMed: 5338605]

100. Barton NW, Brady RO, Dambrosia JM, et al. Replacement therapy for inherited enzyme deficiency-macrophage-targeted glucocerebrosidase for Gaucher's disease. N Engl J Med. 1991;324:1464-1470. [PubMed: 2023606]

101. Brady RO. Emerging strategies for the treatment of hereditary metabolic storage disorders. Rejuvenation Res. 2006;9:237-244. [PubMed: 16706651]

102. Pastores GM, Shankar SP, Petakov M, et al. Enzyme replacement therapy with taliglucerase alfa: 36-month safety and efficacy results in adult patients with Gaucher disease previously treated with imiglucerase. Am J Hematol. 2016;91:661-665. [PubMed: 27102949]

103. Pastores GM, Rosenbloom B, Weinreb N, et al. A multicenter open-label treatment protocol (HGT-GCB-058) of velaglucerase alfa enzyme replacement therapy in patients with Gaucher disease type 1: safety and tolerability. Genet Med. 2014;16:359-366. [PubMed: 24263462]

104. Zimran A, Pastores GM, Tylki-Szymanska A, et al. Safety and efficacy of velaglucerase alfa in Gaucher disease type 1 patients previously treated with imiglucerase. Am J Hematol. 2013;88:172-178. [PubMed: 23339116]

105. Andersson HC, Charrow J, Kaplan P, et al. Individualization of long-term enzyme replacement therapy for Gaucher disease. Genet In Med. 2005;7:105. [PubMed: 15714077]

106. Pastores GM, Weinreb NJ, Aerts H, et al. Therapeutic goals in the treatment of Gaucher disease. Time. 2004;41(4 Suppl 5):4-14.

107. Beutler E, Demina A, Laubscher K, et al. The clinical course of treated and untreated Gaucher disease. A study of 45 patients. Blood Cells Mol Dis. 1995;21:86-108. [PubMed: 8846048]

108. Zimran A, Hadas-Halpern I, Zevin S, et al. Low-dose high-frequency enzyme replacement therapy for very young children with severe Gaucher disease. Br J Haematol. 1993;85:783-786. [PubMed: 7918044]

109. Cohen IJ, Katz K, Kornreich L, et al. Low-dose high-frequency enzyme replacement therapy prevents fractures without complete suppression of painful bone crises in patients with severe juvenile onset type I Gaucher disease. Blood Cells Mol Dis. 1998;24:296-302. [PubMed: 10087987]

110. Wilson C, Spearing R, Teague L, et al. The outcome of clinical parameters in adults with severe Type I Gaucher disease using very low dose enzyme replacement therapy. Mol Genet Metab. 2007;92:131-136. [PubMed: 17604204]

111. Goldblatt J, Fletcher JM, McGill J, et al. Enzyme replacement therapy "drug holiday": results from an unexpected shortage of an orphan drug supply in Australia. Blood cells Mol Dis. 2011;46:107-110. [PubMed: 20684886]

112. Andersson H, Kaplan P, Kacena K, et al. Eight-year clinical outcomes of long-term enzyme replacement therapy for 884 children with Gaucher disease type 1. Pediatrics. 2008;122:11821190. [PubMed: 19047232]

113. Cheema HA, Malik HS, Parkash A, et al. Spectrum of inherited metabolic disorders in Pakistani children presenting at a tertiary care centre. Jcpsp. 2016;26:498-502. [PubMed: 27353988]

114. Radin NS, Arora RC, Ullman MD, et al. A possible therapeutic approach to Krabbe's globoid leukodystrophy and the status of cerebroside synthesis in the disorder. Res Commun Chem Pathol Pharmacol. 1972;3:637-644. [PubMed: 5034520]

115. Shayman JA. Synthesis inhibition therapy for Gaucher disease In: Advances in Gaucher disease: basic and clinical perspectives. Future Medicine Ltd, Grabowski: London; 2013 p. 240-256.

116. Cox T, Lachmann R, Hollak C, et al. Novel oral treatment of Gaucher's disease with Nbutyldeoxynojirimycin (OGT 918) to decrease substrate biosynthesis. Lancet (London, England). 2000;355:1481-1485.

117. Elstein D, Hollak C, Aerts JMFG, et al. Sustained therapeutic effects of oral miglustat (Zavesca, N-butyldeoxynojirimycin, OGT 918) in type I Gaucher disease. J Inherit Metab Dis. 2004;27:757-766. [PubMed: 15505381] 
118. Giraldo P, Alfonso P, Atutxa K, et al. Real-world clinical experience with long-term miglustat maintenance therapy in type 1 Gaucher disease: the ZAGAL project. Haematologica. 2009;94:1771LP-1775. [PubMed: 19608672]

119. Pastores GM, Elstein D, Hrebícek M, et al. Effect of miglustat on bone disease in adults with Type 1 Gaucher disease: a pooled analysis of three multinational. Open-Label Studies. Clin Ther. 2007;29:1645-1654. [PubMed: 17919546]

120. Hollak CEM, Hughes D, Van Schaik IN, et al. Miglustat (Zavesca) in type 1 Gaucher disease: 5year results of a post-authorisation safety surveillance programme. Pharmacoepidemiol Drug Saf. 2009;18:770-777. [PubMed: 19507165]

121. Kuter DJ, Mehta A, Hollak CEM, et al. Miglustat therapy in type 1 Gaucher disease: clinical and safety outcomes in a multicenter retrospective cohort study. Blood Cells Mol Dis. 2013;51:116124. [PubMed: 23683771]

122. Giraldo P, Andrade-Campos M, Alfonso P, et al. Twelve years of experience with miglustat in the treatment of type 1 Gaucher disease: the Spanish ZAGAL project. Blood Cells Mol Dis. 2018;68 (Supplement C):173-179. [PubMed: 27836529]

123. Peterschmitt MJ, Cox GF, Ibrahim J, et al. A pooled analysis of adverse events in 393 adults with Gaucher disease type 1 from four clinical trials of oral eliglustat: evaluation of frequency, timing, and duration. Blood Cells Mol Dis. 2018;68:185-191. [PubMed: 28126395]

124. Zimran A, Goldblatt J, Szer J. Should eliglustat be first line therapy for patients with type 1 Gaucher disease? Definitions of safety and efficacy. Blood Cells Mol Dis. 2017;68:14-16. [PubMed: 28935503]

125. Dulsat C, Mealy N. Isofagomine tartrate. Drugs Fut. 2009;34:23.

126. Therapeutics A Amicus therapeutics announces preliminary results of phase 2 study with plicera for Gaucher disease. zu finden unter. [cited 2018 Jan17]. Available from: http:// ir.amicustherapeutics.com/releasedetail.cfm.

127. Maegawa GHB, Tropak MB, Buttner JD, et al. Identification and characterization of ambroxol as an enzyme enhancement agent for Gaucher disease. J Biol Chem. 2009;284:23502-23516. [PubMed: 19578116]

128. Bendikov-Bar I, Maor G, Filocamo M, et al. Ambroxol as a pharmacological chaperone for mutant glucocerebrosidase. Blood Cells Mol Dis. 2013;50:141-145. [PubMed: 23158495]

129. Narita A, Shirai K, Itamura S, et al. Ambroxol chaperone therapy for neuronopathic Gaucher disease: a pilot study. Ann Clin Trans Neurol. 2016;3:200-215.

130. Aflaki E, Stubblefield BK, Maniwang E, et al. Macrophage models of Gaucher disease for evaluating disease pathogenesis and candidate drugs. Sci Transl Med. 2014;6:240ra273.

131. Aflaki E, Borger DK, Moaven N, et al. A new glucocerebrosidase chaperone reduces a-synuclein and glycolipid levels in iPSC-derived dopaminergic neurons from patients with Gaucher disease and Parkinsonism. J Neurosci off J Soc Neurosci. 2016;36:7441-7452.

132. Jung O, Patnaik S, Marugan J, et al. Progress and potential of non-inhibitory small molecule chaperones for the treatment of Gaucher disease and its implications for Parkinson disease. Expert Rev Proteomics. 2016;13:1-9. [PubMed: 26577456] 


\section{Key issues}

- GD manifests with vast phenotypic heterogeneity ranging from asymptomatic older adults to infants who succumb during the first days of life. Being able to distinguish the different phenotypes is imperative.

- While some genotypes are associated with specific Gaucher phenotypes, predictions are limited. Genetic modifiers likely play a role.

- Different forms of ERT and SRT have a significant effect on disease outcome in patients with GD1 and GD3.

- Current treatments do not significantly change the outcome of GD2.

- $\quad$ Not all identified patients require therapy, but treatment should be administered early in symptomatic children.

- Current therapies remain extremely expensive and are not available to all patients that need them.

- The benefit of combining therapies needs to be further evaluated.

- As infants are increasingly being identified at birth, close monitoring and longitudinal studies will be necessary to better guide the need and criteria for therapeutic interventions. Thus far, screening does not appear to be changing disease management.

- $\quad$ GD is being diagnosed in older adults with PD or multiple myeloma.

- While mutations in $G B A 1$ are a risk factor for parkinsonism, most patients with GD do not develop PD. Current GD therapeutics do not impact parkinsonian manifestations, but new therapies are being considered. 


\section{Box 1.}

\section{Presenting Features by Age}

\section{Newborn}

Congenital ichthyosis

Organomegaly

Failure to thrive

Brain stem dysfunction- dysphagia, apnea, difficulty with secretions

Hepatosplenomegaly

Hematological abnormalities (anemia, thrombocytopenia)

\section{First year of life}

Failure to thrive

Anemia/thrombocytopenia

Brain stem dysfunction- progressive

Saccadic gaze abnormalities

Seizures

Cardiac valvular stenosis

\section{Childhood}

Organomegaly

Hematological abnormalities, including bleeding events

Bone pain crisis

Skeletal/bone involvement-avascular necrosis, osteopenia, pathologic

fractures

Saccadic gaze abnormalities

Myoclonic epilepsy

\section{Adolescence}

Organomegaly

Abnormal bleeding

Delayed puberty

Bone pain crises skeletal/bone involvement 


\section{Box 2.}

\section{Approved First-line Therapies for Gaucher Disease}

Enzyme Replacement Therapy (imiglucerase, velaglucerase alfa, taliglucerase alfa)

- Recombinant enzyme

- $\quad$ Administered intravenously

- $\quad$ Few adverse events

- $\quad$ No demonstration of superiority between the three available ERTs

- Very costly, life-long therapy

- $\quad$ Not effective for GD2

Substrate Reduction Therapy (eliglustat tartrate and miglustat)

- $\quad$ Administered orally

- $\quad$ Approved for use in adults but not children

- $\quad$ Dosage and use depends on rate of CYP2D6 metabolism

- $\quad$ More frequent adverse events than ERT

- $\quad$ Similar cost to ERT, life-long therapy

- $\quad$ Not effective for GD2 


\section{Box 3.}

\section{Unmet Needs in Gaucher Disease}

- Therapy that crosses the blood-brain-barrier

- Less costly therapies

- Identification of other factors that impact including disease severity

- $\quad$ Improved understanding of specific aspects

- $\quad$ Bone disease

- Chronic fatigue and inflammation

- Pulmonary hypertension

- Gaucheromas

- $\quad$ Parkinsonism

- $\quad$ Association with malignancies 


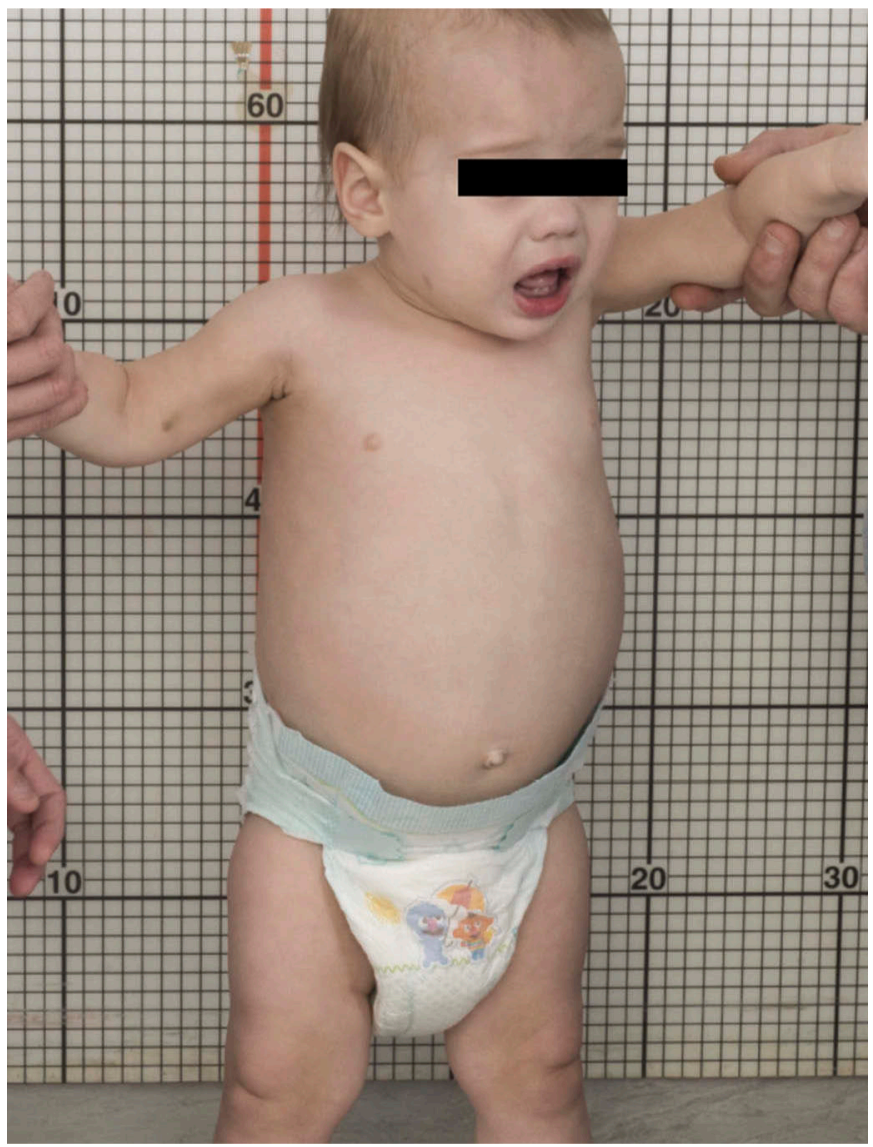

Figure 1.

Photo of an 14-month-old child with hepatosplenomegaly and growth delay, recently diagnosed with Gaucher disease. Because he presented in the first year of life, his parents were initially told that he had type 2 Gaucher disease. While this is clearly not the case, it has been challenging to determine whether he has type 1 or type 3 Gaucher disease. He currently demonstrates no neurological features, yet his genotype is L444P/L444P. Picture with written parent consent. 
Table 1.

Modified from Biegstraaten et al. [98].

\begin{tabular}{|c|c|c|}
\hline & Short-term goals for management of Gaucher disease type 1 & $\begin{array}{l}\text { Long-term goals for management of } \\
\text { Gaucher disease type } 1\end{array}$ \\
\hline \multirow[t]{2}{*}{ Anemia-related symptoms } & Eliminated blood transfusion dependency & Maintain normal hemoglobin values \\
\hline & $\begin{array}{l}\text { Increase hemoglobin levels within 12-24 months to normal values of } \\
\text { age and sex }\end{array}$ & \\
\hline \multirow[t]{3}{*}{ Bleeding tendency } & $\begin{array}{l}\text { Increase platelet counts sufficiently to prevent surgical, obstetrical, and } \\
\text { spontaneous bleeding }\end{array}$ & $\begin{array}{l}\text { Maintain platelet count of } \\
\geq 100,000 / \mathrm{mm}^{3}\end{array}$ \\
\hline & $\begin{array}{l}\text { In patients with splenectomy - normalization of platelet count by } 1 \text { year } \\
\text { of treatment }\end{array}$ & \\
\hline & $\begin{array}{l}\text { In patients with an intact spleen: achieve platelet count of } \\
\geq 100,000 / \mathrm{mm}^{3} \text { by } 3 \text { years of treatment }\end{array}$ & \\
\hline \multirow[t]{5}{*}{ Mobility } & $\begin{array}{l}\text { Lessen bone pain that is not related to irreversible bone disease within } \\
1-2 \text { years }\end{array}$ & $\begin{array}{l}\text { Prevent bone complications: avascular } \\
\text { necrosis, bone crises, bone infarcts, and } \\
\text { pathological fractures }\end{array}$ \\
\hline & $\begin{array}{l}\text { Decrease bone marrow involvement, as measured by a locally used } \\
\text { scoring system (e.g. BMB score or DGS) in patients without severe } \\
\text { irreversible bone disease at baseline }\end{array}$ & $\begin{array}{l}\text { Prevent osteopenia and osteoporosis } \\
\text { (i.e. maintain BMD T-scores (DEXA) } \\
\text { of }>-1 \text { ) }\end{array}$ \\
\hline & $\begin{array}{l}\text { Increase BMD by } 2 \text { years in adults for patients with a } T \text {-score below } \\
-2.5 \text { at baseline }\end{array}$ & $\begin{array}{l}\text { Prevent chronic use of analgesic } \\
\text { medication for bone pain }\end{array}$ \\
\hline & Attain normal or ideal peak skeletal mass in children & $\begin{array}{l}\text { Maintain normal mobility or, if } \\
\text { impaired at diagnosis, improve } \\
\text { mobility }\end{array}$ \\
\hline & $\begin{array}{l}\text { Normalize growth such that the height of the patient is in line with } \\
\text { target height, based upon population standards and parental height, } \\
\text { within } 2 \text { years of treatment }\end{array}$ & \\
\hline \multirow[t]{5}{*}{ Visceral complications } & Avoid splenectomy, if at all possible & $\begin{array}{l}\text { Maintain spleen volume of }<2-8 \text { times } \\
\text { normal }\end{array}$ \\
\hline & $\begin{array}{l}\text { Alleviate symptoms due to splenomegaly: abdominal distension, early } \\
\text { satiety, new splenic infarction }\end{array}$ & $\begin{array}{l}\text { Maintain normal or (near) normal liver } \\
\text { volume }\end{array}$ \\
\hline & Eliminate hypersplenism & $\begin{array}{l}\text { Prevent liver fibrosis, cirrhosis, and } \\
\text { portal hypertension }\end{array}$ \\
\hline & $\begin{array}{l}\text { Reduce spleen volume to }<2-8 \text { times normal (or in absence of volume } \\
\text { measurement tools reduce spleen size) by year } 1-2 \text {, depending on } \\
\text { baseline spleen volume }\end{array}$ & \\
\hline & $\begin{array}{l}\text { Reduce the liver volume to } 1.0-1.5 \text { times normal (or in absence of } \\
\text { volume measurement tools aim for normal liver size) by year } 1-2 \text {, } \\
\text { depending on baseline liver volume }\end{array}$ & \\
\hline \multirow[t]{4}{*}{ General well-being } & $\begin{array}{l}\text { Improve scores from baseline of a validated quality-of-life instrument } \\
\text { within 2-3 years or less depending on disease burden }\end{array}$ & $\begin{array}{l}\text { Maintain good quality of life as } \\
\text { measured by a validated instrument }\end{array}$ \\
\hline & $\begin{array}{l}\text { Reduce fatigue (not anemia related) as measured by a validated fatigue } \\
\text { scoring system }\end{array}$ & $\begin{array}{l}\text { Maintain normal participation in } \\
\text { school and work activities }\end{array}$ \\
\hline & $\begin{array}{l}\text { Improve or restore physical function for carrying out normal daily } \\
\text { activities and fulfilling functional roles }\end{array}$ & $\begin{array}{l}\text { Minimize psychosocial burdens of life- } \\
\text { long treatment }\end{array}$ \\
\hline & & $\begin{array}{l}\text { Achieve normal onset of puberty } \\
\text { Normalize life expectancy }\end{array}$ \\
\hline Pulmonary complications & - & $\begin{array}{l}\text { Prevent or improve pulmonary disease, } \\
\text { pulmonary hypertension, and } \\
\text { hepatopulmonary syndrome }\end{array}$ \\
\hline Pregnancy and delivery & - & $\begin{array}{l}\text { Prevent GD-related complications } \\
\text { during pregnancy and delivery }\end{array}$ \\
\hline
\end{tabular}

BMB: bone marrow burden; BMD: bone marrow density; DGS: düsseldorf Gaucher score. 